\title{
Removal of Metribuzin by Ozonation: Effect of Initial Concentration and $\mathrm{pH}$
}

\author{
Micheline Orlandi Honório ${ }^{1}$, Everson Vaz de Liz Junior ${ }^{1}$, Regina de Fátima Peralta Muniz Moreira ${ }^{1}$, \\ Rênnio Felix de Sena ${ }^{2}$, Humberto Jorge José ${ }^{1}$ \\ ${ }^{1}$ Department of Chemical Engineering and Food Engineering, Federal University of Santa Catarina (UFSC), Florianópolis, Brazil; \\ ${ }^{2}$ Department of Chemical Engineering, Federal University of Paraíba (UFPB), João Pessoa, Brazil. \\ Email: micheline.hermany@hotmail.com
}

Received November $1^{\text {st }}, 2012$; revised January $5^{\text {th }}, 2013$; accepted February $3^{\text {rd }}, 2013$

Copyright (C) 2013 Micheline Orlandi Honório et al. This is an open access article distributed under the Creative Commons Attribution License, which permits unrestricted use, distribution, and reproduction in any medium, provided the original work is properly cited.

\begin{abstract}
Herbicides are chemical compounds capable of killing or inhibiting the growth of certain plants and they have been frequently detected in natural waters. Advanced treatments, including those using ozone, have been used in order to remove herbicides from different types of water with good treatment efficiency. The efficiency of ozonation, an oxidative process, in the removal of persistent compounds is affected by several factors, such as $\mathrm{pH}$ and the concentration of the contaminant. The compound metribuzin, the herbicide investigated in this study, is persistent and mobile in the environment with a high potential for transport through soils and thus it can reach the groundwater. In this context, the objective of this study was to evaluate the effect of different $\mathrm{pH}$ conditions $(2.5,5.5$ and 12.0) and initial concentrations of metribuzin $(20,50$ and $100 \mathrm{ppm})$ on the removal of this herbicide from water using the ozonation process. In order to identify the possible effect of these two variables on the ozonation treatment, the concentration of metribuzin was determined by spectrophotometry UV-vis spectrophotometer. The results were used to evaluate the best conditions for the ozonation treatment. The ozonation conditions which provided the highest metribuzin removal efficiency $(86.5 \% \pm$ $0.3 \%$ ) were $\mathrm{pH} 12.0$ and an initial metribuzin concentration of $20 \mathrm{ppm}$. The findings indicate that oxidation with ozone is effective for the removal of metribuzin from aqueous solutions under the conditions studied.
\end{abstract}

Keywords: Pesticides; Metribuzim; Ozone; Removal

\section{Introduction}

Herbicides are chemical compounds that have the ability to kill or inhibit the growth of certain undesirable plants without disturbing the desired crop [1]. Their frequently detection in water resources, even in very small concentrations, is cause for concern due to the adverse potential effects related to health [2].

The herbicide metribuzin is a synthetic compound of the group triazinone and it is the active principle of Sencor $480 \mathrm{SC}^{\circledR}$, used for controlling weeds in crops, for example, soybean and sugar cane. It is a recalcitrant compound that has high mobility in soil, which may reach the groundwater and thereafter decompose in the soil producing intermediates of lower toxicity. Harmful if swallowed and very toxic to aquatic organisms, this herbicide may cause long-term degradation to the aquatic environment, and for this reason it is considered a potential contaminant of groundwater [3].
Metribuzin $\left(\mathrm{C}_{8} \mathrm{H}_{14} \mathrm{~N}_{4} \mathrm{OS}\right)$, 4-amino-6-tert-butyl-4, 5dihydro-3-methylthio-1, 2, 4-triazin-5-one, is a colorless crystalline solid which has a solubility in water $\left(20^{\circ} \mathrm{C}\right)$ of $1050 \mathrm{ppm}$, maximum absorption in UV-vis range $\left(\lambda_{\max }\right)$ at $294 \pm 1.0 \mathrm{~nm}$ [3] and the structural formula shown in Figure 1. It is moderately hazardous (class II) and when

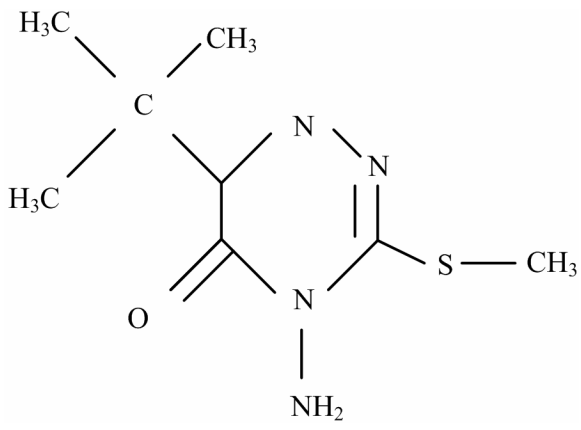

Figure 1. Structural formula of metribuzin. 
the pesticide is absorbed by the target plant it exerts phytotoxic action [3-7].

This herbicide is used in a pre- and post-emergency situation and its action mechanism involves inhibition of photosynthesis. It is highly toxic to algae and microcrustaceans and is persistent and mobile in the environment. Apart from reaching the groundwater [7-10] and it can also contaminate surface water through direct application and runoff $[11,12]$.

The decomposition products of metribuzin in soil, DADK (desamino diketo metribuzin-main product), DK (diketo metribuzin) and DA (desamino metribuzin), are persistent and mobile and can be detected in groundwater $[11,12]$.

New technologies are being used in order to improve the processes for wastewater treatment, reducing the amount of sludge generated and eliminating recalcitrant compounds [13], and these include the Advanced Oxidation Processes (AOPs).

Advanced oxidation processes (AOPs) are attractive alternatives to biological process and non-destructive physical water treatment processes, because they are able to mineralize organic water contaminants. AOP treatments use strong oxidizing agents $\left(\mathrm{O}_{3}, \mathrm{H}_{2} \mathrm{O}_{2}\right)$ and/or catalysts $\left(\mathrm{Fe}, \mathrm{Mn}, \mathrm{TiO}_{2}\right)$ usually together with high-energy radiation, e.g., UV irradiation. AOPs predominantly involve the generation of a very powerful and non-selective oxidizing species, the hydroxyl $\operatorname{radical}(\bullet \mathrm{OH})$, for the destruction of persistent and hazardous pollutants [13].

Ozone is a chemical compound with a triatomic structure $\left(\mathrm{O}_{3}\right)$ and it is a resonance hybrid (Figure 2). Also, it is toxic, colorless, sparingly soluble in water and easily detected at very low concentrations $\left(0.01-0.05 \mathrm{mg} \cdot \mathrm{L}^{-1}\right)$ [14]. Its properties derive from its high reactivity which can be attributed to the electronic configuration of the molecule due to the electrophilic character of ozone (confirmed by the absence of electrons in one of the terminal oxygen atoms in some of the resonance structures) and an excess negative charge present in some another oxygen atoms imparts a nucleophilic character [15].

Different applications of ozone have been studied by several authors, such as the treatment of drinking water, cooling water, treatment of industrial effluents with a high content of organic compounds, cleaning and disinfection of fruits, vegetables and processed meat, liquor and slurry treatment, use in industrial laundries and bleaching processes, treatment of domestic sewage and Industrial cleaning pools.

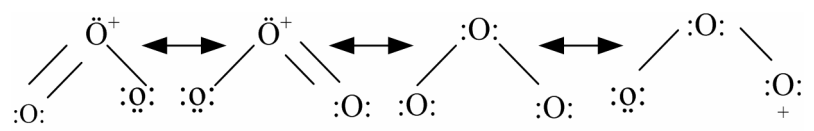

Figure 2. Canonical structures of resonance hybrid of the ozone molecule [16].
Due to its oxidation potential $\left(\mathrm{E}_{0}=2.07 \mathrm{~V}\right)$, ozone has been used in technologies which are capable of reducing and removing a number of environmental pollution parameters, proving very effective, for example, in the removal of organic matter in the treatment of water [17].

Based on the ability of ozone to react with organophosphate and organonitrogen insecticides, such processes have proven to be effective for the elimination of different pesticides in wastewater, especially when the reaction occurs in alkaline medium, when compared to other AOPs, such as the photo-Fenton process and photocatalysis with $\mathrm{TiO}_{2}[18]$.

Because of this, AOPs, such as those employing $\mathrm{O}_{3}$ $\left(\mathrm{O}_{3}\right.$ in alkaline medium; $\mathrm{O}_{3} / \mathrm{H}_{2} \mathrm{O}_{2} ; \mathrm{O}_{3} / \mathrm{UV} ; \mathrm{O}_{3} / \mathrm{H}_{2} \mathrm{O}_{2} / \mathrm{UV}$; $\mathrm{O}_{3}$ /catalyst), have been considered a viable treatment alternative when the contaminated material has a low concentration of organic compounds (hundreds of ppm) and the contaminants are not biodegradable. In addition, the AOPs can be used when the conventional treatment is not feasible or even inappropriate, for example, effluents containing toxic compounds or mixtures which contain complex compounds and/or high concentrations of contaminants [17].

Ozonation can occur by two mechanisms, the direct attack of $\mathrm{O}_{3}$ molecules (direct reaction) and attack by the hydroxyl radical $(\cdot \mathrm{OH})$, formed in the decomposition of ozone (indirect reaction).

The direct ozonation reactions are highly selective relatively slow $\left(\mathrm{k}_{\mathrm{D}}=1-10^{3} \mathrm{M}^{-1} \cdot \mathrm{s}^{-1}\right)$ and limited to aromatic and aliphatic acids. Among the compounds that react with ozone by direct reaction are those containing $\mathrm{C}=\mathrm{C}$ bonds, specific functional groups $\left(\mathrm{OH}, \mathrm{CH}_{3}, \mathrm{OCH}_{3}\right)$ and atoms which have a negative charge density $(\mathrm{N}, \mathrm{P}, \mathrm{O}$ and S) $[9,16]$.

The indirect reaction is not selective since it can easily and quickly react with many compounds present in the water by means of the $\cdot \mathrm{OH}$ radical $\left(\mathrm{E}_{0}=2.80 \mathrm{~V}\right)$. This radical is able to promote an attack on organic compounds $10^{6}-10^{9}$ times faster than known oxidizing agents such as $\mathrm{H}_{2} \mathrm{O}_{2}\left(\mathrm{E}_{0}=1.77 \mathrm{~V}\right)$ and $\mathrm{O}_{3}$ itself $\left(\mathrm{E}_{0}=\right.$ $2.07 \mathrm{~V})[9]$.

Ozone $\left(\mathrm{O}_{3}\right)$, although highly efficient, restricts the mineralization of organic micropollutants in potable water or industrial effluents, which is verified by the low rates of TOC removal, even using AOPs (with $\mathrm{O}_{3}$ ) [17].

The efficiency of ozonation, when used in the treatment of natural waters is influenced by several factors such as the $\mathrm{pH}$ and temperature of the medium, type and concentration of the contaminant and ozone flow rate.

The $\mathrm{pH}$ is the factor that deserves special attention since; in general, the hydroxyl ions catalyze this reaction because they alter the stability of ozone in the medium in relation to the formation of hydroxyl radicals (more reactive species). Therefore, it is considered the main vari- 
able that affects ozonation [13,19].

In relation to the contaminant, studies indicate that increasing the initial concentration causes an increase in the consumption of ozone when the amount of organic matter to be oxidized is increased, decreasing the concentration of residual ozone, this behavior being accenttuated at the beginning of ozonation. Therefore, at lower contaminant concentrations the removal occurs more rapidly [20,21].

In this context, this study aimed to evaluate the removal of metribuzin applying an ozonation process under different conditions of $\mathrm{pH}$ and initial metribuzin concentrations.

\section{Materials and Methods}

All solutions containing metribuzin were prepared using distilled water and the commercial product Sencor ${ }^{\circledR}$ SC 480 (48\% metribuzin).

The $\mathrm{pH}$ was adjusted to $\mathrm{pH} 2.5,5.5$ or 12.0 using diluted $\mathrm{H}_{2} \mathrm{SO}_{4}$ and $\mathrm{NaOH}$. The tert-butanol (VETEC) was used as a scavenger of hydroxyl radicals in an ozone to tert-butanol ratio of 1:1000, at the beginning of the reaction.

An ozone generator (TECH FILTER) was used to produce the ozone from the ambient air, applying the principle of electrochemical discharge (corona), capable of producing $500 \mathrm{mg} \cdot \mathrm{O}_{3} \cdot \mathrm{h}^{-1}$.

A batch reactor was used, formed by a cylindrical outer jacket of borosilicate glass, with a water inlet and outlet, where the temperature of the water is monitored, with a working volume of $1.5 \mathrm{~L}$. The bubbling gas is conducted through two porous cylindrical dispersers. The samples were collected with a syringe coupled to a silicone tube. During all runs agitation was applied in the reactor, as shown in Figure 3.

\subsection{Analytical Determinations}

The remaining concentration of metribuzin at different reaction times was determined using a UV-vis spectrophotometer (HACH 5000) at $293 \mathrm{~nm}$. The $\mathrm{pH}$ was measured with a $\mathrm{pH}$ meter (PH LUTHORN 206).

\subsection{Experimental Conditions}

Initially, experiments were performed at $\mathrm{pH} 12.0$ and $\mathrm{pH}$ 5.5 without ozone, in order to verify the effect of $\mathrm{pH}$ on the stability of metribuzin. The metribuzin (20 ppm) was then added to the distilled water at $\mathrm{pH} 12.0$ and $\mathrm{pH} 2.5$ without ozone, and the concentration of metribuzin ([MTZ]) was quantified at predetermined intervals during a period of $240 \mathrm{~min}$.

The ozonation experiments were firstly conducted at different $\mathrm{pH}$ values $(2.5,5.5$ and 12.0) with an initial

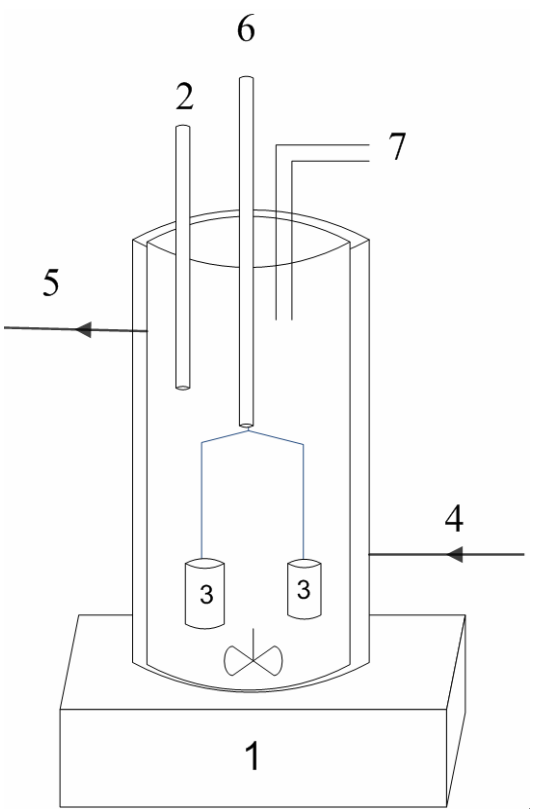

Figure 3. Ozonation system used (1-magnetic stirrer, 2point of sample collection; 3 - cylindrical bubblers, 4 -inlet for water from thermostatic bath, 5-water outlet to water bath, 6-reactor bath, 7-ozone residual output).

concentration of metribuzin of $20 \mathrm{ppm}$. The concentration of metribuzin was then varied (20,50 and $100 \mathrm{ppm})$ and an initial $\mathrm{pH}$ of 5.5 was used, with and without tertbutanol.

All experiments were performed with an ozone concentration in the gas phase of $500 \mathrm{ppm}$ and flow rate of $1.1 \mathrm{~L} \mathrm{O}_{3} \cdot \mathrm{h}^{-1}$, which was maintained constant. The solution temperature was maintained at $21^{\circ} \mathrm{C}$ in a thermostatic bath (QUIMIS ${ }^{\circledR}$ ).

The $\mathrm{O}_{3} / \mathrm{O}_{2}$ gas mixture was bubbled through the reactor with a constant flow of ozone for $1 \mathrm{~h}$. After reaching the complete solubility of the ozone a volume appropriate to achieve the desired concentrations of metribuzin was added, maintaining the bubbling constant for the whole reaction period $(240 \mathrm{~min})$. The aliquots were collected at predetermined intervals from the moment of addition of the herbicide to complete 4 hours of reaction.

By quantifying the concentration of metribuzin, through the absorbance measured by UV-vis spectrophotometer at $293 \mathrm{~nm}$, at predetermined intervals during the reaction, it was possible to evaluate both the effect of the initial metribuzin concentration and of the initial $\mathrm{pH}$ on the removal.

\section{Results and Discussion}

\subsection{Study on the Effect of the Initial Concentration of Metribuzin}

The effect of the initial concentration of metribuzin on the removal efficiency was investigated. 
The metribuzin removal efficiency for initial concentrations of 20, 50 and $100 \mathrm{ppm}$ after $240 \mathrm{~min}$ of reaction was evaluated. Figure 4 shows the evolution of the metribuzin removal applying ozonation at an initial $\mathrm{pH}$ of 5.5 for different initial concentrations of metribuzin.

It can be observed that the removal of the metribuzin, at the concentrations studied, slowly reaches removals of $58.6 \% \pm 6.2 \%, 30.5 \% \pm 0.4 \%$ and $16.7 \% \pm 3.1 \%$ for concentrations of 20,50 and 100 ppm, respectively.

The metribuzin removal efficiency, by ozonation, decreased with increasing initial concentrations of metribuzin because, according to the literature $[15,21]$, there is a greater consumption of ozone when the amount of organic matter to be oxidized is increased, decreasing thus the concentration of residual ozone. Therefore, at lower contaminant concentrations the removal occurs more rapidly.

\subsection{Effect of pH}

The $\mathrm{pH}$ affects the mechanism by which the ozone oxidizes the organic molecules in the effluent and can also influence the stability of the molecules.

According to IUPAC [3], metribuzin is stable at between $\mathrm{pH} 5$ and 9. Therefore, experiments were conducted to evaluate the effect of the $\mathrm{pH}$ (2.5 and 12.0) on the stability of metribuzin using an initial concentration of 20 ppm (Figure 5).

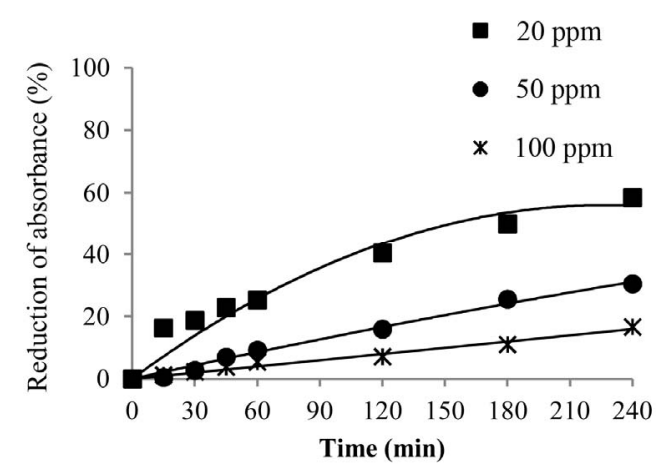

Figure 4. Evolution of metribuzin removal with different initial concentrations of metribuzin ( $\mathrm{pH}$ 5.5).

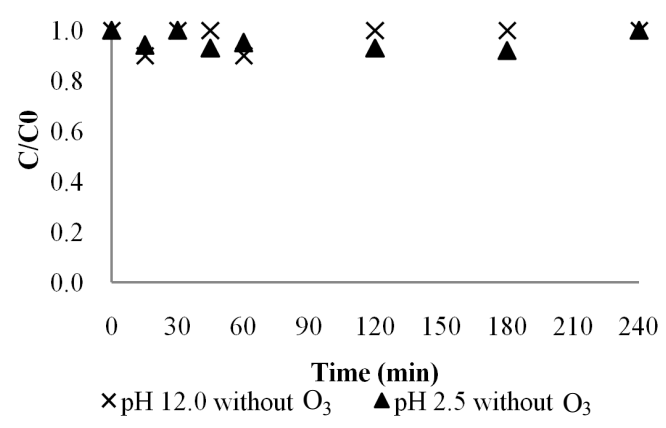

Figure 5. Effect of pH (2.5 and 12) on the stability of metribuzin $\left(\left[\mathrm{MTZ}_{0}\right]=20 \mathrm{ppm}\right)$ without ozone.
It can be seen that there was no difference in the concentration of metribuzin measured during the reaction period (240 $\mathrm{min}$ ) at the two $\mathrm{pH}$ values, indicating that under the conditions studied metribuzin remained stable since there was no decrease in the metribuzin concentration (Figure 5). Thus, it can be considered that during the ozonation process the decrease in the metribuzin concentration observed is due only to oxidation by ozone.

Thus, studies were initiated to evaluate the effect of different $\mathrm{pH}$ values on the metribuzin removal efficiency from an aqueous solution by ozonation with an initial metribuzin concentration of $[\mathrm{MTZ}]_{0}=20 \mathrm{ppm}$, ozone flow (Q) of $1.1 \mathrm{~L} \cdot \mathrm{h}^{-1}$ and system temperature (T) of $20^{\circ} \mathrm{C}$ $\pm 1^{\circ} \mathrm{C}$ for $240 \mathrm{~min}$.

Figure 6 shows the percent removal of metribuzin as a function of the initial $\mathrm{pH}$, for 240 minutes, when the ozonation process was applied.

It can be observed that during the ozonation process (240 min) at alkaline $\mathrm{pH}(\mathrm{pH} 12.0)$, the removal of metribuzin was $86.5 \% \pm 0.3 \%$, which was higher than at acidic $\mathrm{pH}(\mathrm{pH} 5.5$ and $\mathrm{pH} 2.5)$, where the removals obtained were $58.5 \% \pm 6.3 \%$ and $64.5 \% \pm 4.0 \%$, respecttively. Hence, most of the metribuzin removal at alkaline $\mathrm{pH}$ probably occurred through indirect oxidation with hydroxyl radicals, which have a higher oxidation potential than molecular ozone.

Under acidic conditions, either there is a higher molecular ozone concentration in the medium or compounds, such as metribuzin, with $\mathrm{C}=\mathrm{C}$ bonds, specific functional groups $\left(\mathrm{OH}, \mathrm{CH}_{3}, \mathrm{OCH}_{3}\right)$ and atoms that possess a negative charge density $(\mathrm{N}, \mathrm{P}, \mathrm{O}$ and $\mathrm{S})$ react with molecular ozone in a selective manner [9,22]. Moreover, at alkaline $\mathrm{pH}$, there is the decomposition of ozone (particularly to the hydroxyl radical $(\mathrm{OH} \bullet))$ which does not react selectively with this type of compound and thus the removal of metribuzin, when applying ozonation at $\mathrm{pH}$ 12.0, was the most effective.

It was found that under the acidic conditions evaluated, there was a small difference in the metribuzin removal efficiency. Therefore, to better evaluate the influence of

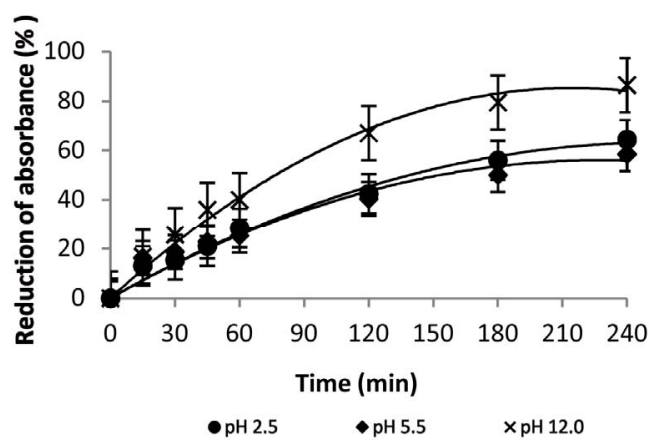

Figure 6. Evolution of metribuzin removal at different $\mathrm{pH}$ values, $\left([\mathrm{MTZ}]_{0}=20 \mathrm{ppm} ; \mathrm{Q}=1.1 \mathrm{~L} \mathrm{O}_{3} \mathrm{~h}^{-1}, \mathrm{~T}=20^{\circ} \mathrm{C} \pm\right.$ $\left.1^{\circ} \mathrm{C}\right)$. 


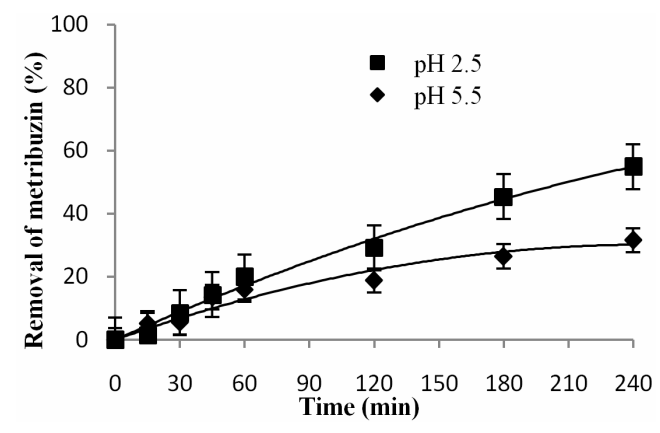

Figure 7. Evolution of metribuzin removal at different acid pH values $\left(\left[\mathrm{MTZ}_{0}\right]=20 \mathrm{ppm} ; \mathrm{Q}=1.1 \mathrm{~L} \mathrm{O}_{3} \cdot \mathrm{h}^{-1} ;\left[\mathrm{O}_{3}\right]:[\right.$ tertbutanol] = 1:1000).

Table 1. Comparison of the efficiency obtained in the ozonation with and without tert-butanol.

\begin{tabular}{cccc}
\hline $\mathrm{pH}$ & $\begin{array}{c}\text { Without } \\
\text { Tert-butanol }^{*}(\%)\end{array}$ & $\begin{array}{c}\text { With } \\
\text { Tert-butanol }^{*}(\%)\end{array}$ & $\mathrm{D}(\%)^{* *}$ \\
\hline 2.5 & $64.5 \pm 4.0$ & $54.9 \pm 0.1$ & 9.6 \\
5.5 & $58.5 \pm 6.3$ & $31.6 \pm 1.4$ & 26.9 \\
\hline
\end{tabular}

* (mean \pm standard deviation); ${ }^{* *} \mathrm{D}=$ Difference between the average efficiencies obtained.

$\mathrm{pH}$ when applying ozonation to remove MTZ at acidic $\mathrm{pH}$, tert-butanol (scavenger of hydroxyl radicals) was added at a concentration 1000 times greater than the ozone dissolved in the medium, to ensure that all hydroxyl radicals generated were consumed [9].

Figure 7 shows the evolution of metribuzin removal during the ozonation treatment, at $\mathrm{pH} 2.5$ and $\mathrm{pH} 5.5$, with tert-butanol.

In the presence of tert-butanol the efficiency of the metribuzin removal decreased compared to reactions performed without tert-butanol. This is because in the first case only the ozone is present, a selective compound that has a lower oxidative potential when compared to the hydroxyl radical.

Thus, to directly determine the prevalence of ozonation in the reactions at $\mathrm{pH} 5.5$ and $\mathrm{pH} 2.5$ the removal efficiencies were compared to those with and without tert-butanol at both $\mathrm{pH}$ values, as shown in Table 1.

Therefore, metribuzin is attacked both by the ozone and the free radicals, in the absence of tert-butanol. On the other hand, in the presence of tert-butanol only ozone acts as an oxidant and as a consequence the removal efficiency is lower at both $\mathrm{pH}$ values. This behavior is most evident at $\mathrm{pH} 5.5$, where the ozone concentration is less than at $\mathrm{pH} 2.5$.

Thus, a direct mechanism predominates at $\mathrm{pH} 2.5$ and 5.5 , although at $\mathrm{pH} 5.5$ both mechanisms (direct and indirect) are operating.

\section{Conclusions}

In this study, two parameters that affect the oxidation process, that is, metribuzin concentration and solution $\mathrm{pH}$, were evaluated. According to the results obtained, under the operation conditions studied, the following conclusions can be drawn.

When the ozone concentration was constant and ozone was the limiting reagent in the reaction, the efficiency of the process decreased with an increase in the initial concentration of metribuzim ( $20 \mathrm{ppm}>50 \mathrm{ppm}>100 \mathrm{ppm})$.

When the ozonation was performed in the absence of tert-butanol at different $\mathrm{pH}$ values, it was observed that the removal of metribuzin was lower at acidic $\mathrm{pH}$ compared with basic $\mathrm{pH}$ due to the concentration of hydroxyl radicals (which have a higher oxidation potential than molecular ozone) being greater at alkaline $\mathrm{pH}$.

The efficiency of the ozonation in the presence of tert-butanol at $\mathrm{pH} 5.5$ and 2.5 was lower than that performed without tert-butanol since in the latter case there is a predominance of the reaction with molecular ozone, the concentration of which decreases with increasing $\mathrm{pH}$.

Thus, the ozonation process that presented the best removal efficiency $(86.5 \% \pm 0.3 \%)$ was that applying $\mathrm{pH}$ 12.0 , initial metribuzin concentration of $20 \mathrm{ppm}$, temperature of $21^{\circ} \mathrm{C}$ and reaction time of $240 \mathrm{~min}$. Under these conditions ozone treatment represents an effective method for the removal of metribuzin.

\section{REFERENCES}

[1] N. D. Kruze, "Biologia e Controle de Plantas DaninhasUnidade 4-Herbicidologia," UFSM, 2012. http://w3.ufsm.br/herb/Unidade\%204.pdf

[2] K. V. Plakas and A. J. Karabelas, "Removal of Pesticides from Water by NF and RO Membranes-A Review," Desalination, Vol. 287, 2012, pp. 255-265. doi:10.1016/j.desal.2011.08.003

[3] IUPAC, "Global Availability of Information on Agrochemicals," 2011.

http://sitem.herts.ac.uk/aeru/iupac/index.htm

[4] P. Chelme-Ayala, M. G. El-Din and D. W. Smith, "Kinetic and Mechanism of Degradation of Two Pesticide in Aqueous Solutions by Ozonation," Chemosphere, Vol. 78, No. 5, 2010, pp. 557-562. doi:10.1016/j.chemosphere.2009.11.014

[5] WHO, "The WHO Recommended Classification of Pesticides by Hazard and Guidelines to Classification 2009". http://www.inchem.org/documents/pds/pdsother/class_20 09.pdf

[6] L. Maraschin, “Avaliação do Grau de Contaminação por Pesticidas na Água dos Principais Rios Formadores do Pantanal Mato-Grossense," Dissertação (Mestrado em Saúde e Ambiente)-Universidade Federal de Mato Grosso, Cuiabá, 2003.

[7] L. Vargas and E. S. Roman, "Resistência de Plantas Daninhas a Herbicidas: Conceitos, Origem e Evolução," 2006.

[8] M. Patterson, "Metribuzin Analysis of Risks to Endan- 
gered and Threatened Salmon and Steelhead," 2004. http://www.epa.gov/espp/litstatus/effects/metribuzin/metr ibuzin_analysis.pdf

[9] D. B. Luiz, A. K. Genena, E. Virmond, J. H. Jose, R. F. P. M. Moreira, W. Gebhardt and H. Fr. Schröder, "Identification of Degradation of Erythromycin A Arising from Ozone and Advanced Process Treatment," Water Environment Research, Vol. 82, No. 9, 2010, pp. 797-805. doi:10.2175/106143010X12609736966928

[10] ANVISA - "Portaria No. 10/SNVS de 08 de Março de 1.985," DOU 14/03/85.

[11] J. C. Barreiro and M. O. O. Rezende, "Estudo da Degradação do Herbicida Metribuzin em Solo na Presença de Ácido Húmico Extraído de Vermicomposto," IV Encontro Brasileiro de Substâncias Húmicas, Vol. 1, 2001, pp. 160-161.

[12] Minnesota Department Health, "Metribuzin Degradates (DA, DK, DADK). Drinking Water Contaminants of Emerging Concern Program," Junho, 2010. http://www.health.state.mn.us/divs/eh/risk/guidance/dwec /summetribuzin.pdf

[13] R. F. Sena, J. L. Tambosi, A. K. Genena, R. F. P. M. Moreira, H. F. R. Schröder and H. J. Jose, "Treatment of Meat Industry Wastewater Using Dissolved Air Flotation and Advanced Oxidation Processes Monitored by GC-MS and LC-MS," Chemical Engineering Journal, Vol. 152, No. 1, 2009, pp. 151-157. doi:10.1016/j.cej.2009.04.021

[14] L. C. M. Filho, "Avaliação da Ozonização Como pré ou pós-Tratamento à Filtração Direta Descendente na Remoção de Cianobactérias e Saxitoxinas," Tese (Doutorado em Engenharia Ambiental), Universidade Federal de Santa Catarina-Florianópolis, 2006.
[15] F. J. Beltrán, “Ozone Reaction Kinetic for Water and Wastewater Systems," Lewis Publishers, CRC Press, USA, 2004, 358 p.

[16] C. Gottschank, J. A. Libra and A. Saupe, "Ozonation of Water and Wastewater: A Practical Guide to Understanding Ozone and Its Application," Willey-VCH, 2000.

[17] C. P. A. B. Teixeira and W. F. Jardim, "Processos Oxidativos Avançados Conceitos Teóricos," Caderno Temático, Universidade Estadual de Campinas-UNICAMP, Campinas. 2004. http://lqa.iqm.unicamp.br/cadernos/caderno3.pdf

[18] E. Almeida, M. R. Assalin, M. A. Rosa and N. Duran, "Tratamento de Efluentes Industriais por Processos Oxidativos na Presença de Ozônio," Química Nova, Vol. 27, No. 5, 2004. doi:10.1590/S0100-40422004000500023

[19] K. Li, A. Yediler, M. Yang, S. Schulte-Hostede and M. H. Wong, "Ozonation of Oxytetracycline and Toxicological Assessment of Its Oxidation By-Products," Chemosphere, Vol. 72, No. 3, 2008, pp. 473-478. doi:10.1016/j.chemosphere.2008.02.008

[20] M. R. Assalin, P. L. Silva and N. Durán, "Comparação da Eficiência do Processo de Ozonização e Ozonização Catalítica (Mn II e Cu II) na Degradação de Fenol,” 2006.

[21] D. A. Coelho, "Degradação dos Antiinflamatórios Diclofenaco, Ibuprofeno e Naproxeno por Ozonização," Tese (Doutorando em Engenharia Química), Universidade Federal do Rio de Janeiro-Rio de Janeiro, 2008.

[22] L. M. Silva, M. H. P. Santana and J. F. C. Boodts, "Electrochemistry and Green Chemical Processes: Electrochemical Ozone Production," Química Nova, Vol. 26, No. 6, 2003, pp. 880-888. doi:10.1590/S0100-40422003000600017 